\title{
Efek Sosiologi Edmodo Sebagai Media Komunikasi Di Era Pandemi Covid 19 Pada Pembelajaran Daring
}

\author{
Sugiyonol, Khuma Ayu Fajar ${ }^{2}$ \\ IAI Darussalam Blokagung Banyuwangi 1,2 \\ Email : sugiyono@iaida.ac.id ${ }^{1}, \underline{\text { khmaayu@gmail.com }}{ }^{2}$
}

\begin{abstract}
Abstrak
Edmodo adalah sebuah platform pembelajaran sosial untuk dosen, mahasiswa maupun untuk orang tua/wali yang dikembangkan pada akhir 2008 oleh Nic Borg dan Jeff. yang merasakan kebutuhan untuk berkembang di lingkungan sekolah/kampus untuk mencerminkan bahwa dunia yang semakin global dan terhubung, maka keduanya menciptakan sebuah alat/aplikasi yang dapat menutup kesenjangan antara bagaimana siswa/mahasiswa menjalani kehidupan mereka dan bagaimana mereka belajar di sekolah/kampus, untuk itulah maka Edmodo ada.Dalam penggunaan edmodo terdapat efek yang terjadi dalam proses komunikasi. penelitian ini menggunakan metode Analisis Domain (Domain analysis) sebab data tentang efek edmodo sebagai media komunikasi di era pandemik, akan di laksanakan sebagai tempat penelitian di lapangan. Maksudnya hasil penelitian tersebut hanya ditargetkan untuk mendapatkan gambaran selengkapnyadari suatu objek yang diteliti, tanpa perlu dirincikan secara rinci unsur-unsur yang terdapat dalam keutuhan objek yang diteliti tersebut. Dengan demikian efek edmodo sebagai media komuniksai di era pandemi covid 19 pada mahasiswa Komunikasi Dan Penyiaran Islam (KPI) adalah positif dan negatif.
\end{abstract}

\section{Kata Kunci :Efek Edmodo, Perkuliahan}

\begin{abstract}
Edmodo is a social learning platform for lecturers, students and for parents / guardians developed in late 2008 by Nic Borg and Jeff. who feel the need to develop in a school / campus environment to reflect that the world is increasingly global and connected, they create a tool I application that can close the gap between how students live their lives and how they learn in school / campus, that's why then Edmodo is there. In using edmodo there are effects that occur in the communication process. This research uses Domain analysis method because data about the effect of Edmodo as a communication medium in the pandemic era will be carried out as a research site in the field. This means that the results of the research are only targeted to obtain a complete picture of the object under study, without the need to specify in detail the elements contained in the integrity of the object under study. Thus the effect of Edmodo as a communication medium in the Covid 19 pandemic era on Islamic Communication and Broadcasting (KPI) students is positive and negative.
\end{abstract}

Keywords: Edmodo effect, lectures

15 Efek Sosiologi Edmodo Sebagai Media Komunikasi Di Era Pandemi Covid 19 Pada Pembelajaran Daring Sugiyono, Khuma Ayu Fajar 


\section{J]}

\section{A. PENDAHULUAN}

\section{Perkembangan teknologi} komunikasi dan media social saat ini berlangsung begitu pesat dan cepat.Informasi apapun dapat diakses dengan mudah di manapun dan kapanpun melalui smartphone, tablet dan laptop yang terkoneksi dengan jaringan internet. Adanya akses internet secara tidak langsung mempengaruhi cara belajar peserta didik dalam mencari informasi terkait dengan materi yang mereka pelajari. Hal ini dapat kita lihat dari kecenderungan mahasiswa ketika mendapat tugas dari dosen, salah satunya diselesaikan dengan browsing di internet.

Pemanfaatan teknologi dalam proses pembelajaran mendorong terciptanya beragam media pembelajaran (perkuliahan) yang biasa dipilih pendidik untuk digunakan dalam pembelajaran (perkuliahan). Hamalik (2011) menjelaskan bahwa teknologi adalah pembawa pesan yang dapat dimanfaatkan untuk keperluan pembelajaran (perkuliahan).Selain itu juga adanya kemajuan dibidang teknologi informasi melahirkan konsep baru dalam pembelajaran yang berbasis IT atau yang lebih dikenal dengan e-learning. E-learning merupakan system pembelajaran elektronik yang memungkinkan peserta didik untuk dapat mengeksplorasi sekaligus juga dapat menjadi jembatan untuk melakukan pembelajaran kapan dan dimana saja (Zhang Et.Al.,2006). Pembelajaran dengan e-learning tidak terlepas dari penggunaan internet yang merupakan akses penting. Daryanto (2013) menjelaskan bahwa karena sifat internet yang dapat dihubungi setiap saat, artinya memanfaatkan programprogram pendidikan yang disediakan di jaringan internet kapan saja sesuai dengan waktu luang mereka.

Salah satu media yang dapat dimanfaatkan dalam proses pembelajaran (perkuliahan) elearning adalah edmodo. Edmodo adalah sebuah platform pembelajaran sosial untuk guru/dosen, siswa/mahasiswa maupun untuk orang tua/wali yang dikembangkan pada akhir 2008 oleh Nic Borg dan Jeff. yang merasakan kebutuhan untuk berkembang di lingkungan sekolah/kampus untuk 


\section{J]}

mencerminkan bahwa dunia yang semakin global dan terhubung, maka keduanya menciptakan sebuah alat/aplikasi yang dapat menutup kesenjangan antara bagaimana siswa/mahasiswa menjalani kehidupan mereka dan bagaimana mereka belajar di sekolah/kampus, untuk itulah maka Edmodo Oxford University Press dan Cambridge University Pressada.

Pada tahun 2013, Edmodo dimasukkan ke dalam daftar "Aplikasi Teratas untuk Guru" oleh PC Magazine. Pada tahun yang sama, Edmodo mengakuisisi startup Root-1 dalam upaya untuk menjadi toko aplikasi untuk pendidikan. Vibhu Mittal, Co-founder dan CEO dari Root-1, menjadi CEO dari Edmodo tahun berikutnya.

Pada tahun 2014, Edmodo meluncurkan Snapshot - seperangkat alat penilaian untuk mengukur kemajuan siswa pada standar pendidikan. Edtech digest memberikan penghargaan untuk Edmodo Snapshot dalam Cool Tool Award sebagai Solusi Penilaian Terbaik. Perusahaan ini telah bermitra dengan dua penerbit besar di Inggris, untuk menyediakan akses ke konten pendidikan di Edmodo Platformdan membawa Edmodo Snapshot ke Inggris.

Pada Agustus 2016 Edmodo diklaim memiliki lebih dari 66.900.000 pengguna di seluruh dunia.Pada bulan Maret 2015, Noodle menyebut Edmodo sebagai salah satu "32 Alat Pendidikan Daring Paling Inovatif".(https://id.wikipedia.org/wi $\underline{\mathrm{ki} / \text { Edmodo) }}$

Menurut Gatot (2013, hlm. 3) "Edmodo adalah platform media sosial yang sering digambarkan seperti Facebook untuk sekolah/kampus dan dapat berfungsi lebih banyak lagi sesuai kebutuhan".Edmodo merupakan media yang menarik untuk guru/dosen, siswa/mahasiswa maupun untuk orang tua/wali dengan elemen sosial yang menyerupai Facebook.

(Gary, 2001, hlm. 6-54), Edmodo adalah jejaring sosial pribadi bagi guru dan siswa dengan platform sosial yang aman.Dengan model kicauan seperti situs jejaring sosial pada umumnya, Edmodo dapat menjadikan jaringan khusus bagi 


\section{J]}

guru dan siswa untuk berbagi ide, berkas, peristiwa, dan tugas.

(Wankel, 2011, hlm. 24), Edmodo adalah jejaring sosial dan layanan micro blogging yang di desain khusus untuk dunia pendidikan, yang dapat dioperasikan seperti 20 layaknya Twitter.Dengan membatasi jalan akses ke ruang khusus atau grup, guru dan siswa dapat saling mengirim catatan, link, berkas, pengumuman, tugas dan bertukar informasi di lingkungan yang aman.

(Purcell, 2012, hlm. 14), Edmodo adalah website yang dapat dijadikan sebuah wadah atau forum diskusi oleh kaum pembelajar yang memiliki tampilan latar seperti Facebook atau Myspace. Pengguna Edmodo dapat membuat profil dan berbincang dengan orang lain yang terhubung dalam website tersebut. Selain itu siswa juga dapat meminta informasi kepada guru tentang nilai atau tugas, dan guru dapat mengunggah nilai siswa dan tugas di dalam web tersebut

(Nurita, 2011), Edmodo merupakan social network berbasis lingkungan sekolah (school based environment) yang dapat dimanfaatkan secara langsung tanpa harus menyediakan server khusus dan instalasi panjang yang dapat digunakan oleh guru dan siswa dalam suatu ruang kelas dengan fitur-fitur pendukung proses belajar mengajar

Fitur utama edmodo adalah dukungan aktif terhadap model komunikasi dari sosial media online. Edmodo memiliki banyak fitur yang dapat digunakan untuk pelaksanaan pembelajaran (perkuliahan) . Fiturfitur tersebut dapat dimanfaatkan sesuai dengan kebutuhan dosen dan mahasiswa masing masing yang memiliki kebutuhan tidak sama. Fitur-fitur Edmodo diantaranya adalah:

1. Group

Fitur ini dimanfaatkan oleh guru untuk membuat grup atau kelas dalam Edmodo. Guru dapat menambahkan siswa untuk bergabung ke dalam grup yang sudah dibuat oleh guru. Kontrol grup ada pada guru.

2. Note

Note digunakan untuk menulis catatan, fungsi catatan ini sama halny dnean guru ketika 


\section{J]}

berbicara didepan kelas. Guru juga bisa melampirkan berbagai jenis file ketika mengirimkan catatan

3. Alert

Alert fungsinya hampir sama dengan note, hanya saja alert lebih ringkas dan tidak bisa dilampirkan file.

\section{Assigment}

Assigment digunakan guru untuk memberikan tugas kepada siswa.tugas tersebut dapat berupa soal uraian pendek maupun esai. Guru juga dapat memberikan soal dari sumber di internet yang sudah dilampirkan.

\section{Quiz}

Quis digunakan untuk memberikan ulangan harian dan ujian dengan bentuk soal pilihan ganda. Soal harus dibuat langsung dan juga tidak bisa dilampirkan file.

\section{Polling}

Polling digunakan oleh guru untuk mengetahui pendapat siswa mengenai sesuatu, baik yang berhubungan dengan materi pelajaran maupun hal lain.

7. Library

Libraly fungsinya adalah untuk menyimpan semua file yang ada di Edmodo. Beragam jenis file dapat disimpan di library dan juga dapat disambungkan dengan aplikasi google drive.

\section{Progress}

9. Guru dapat melihat kemajuan belajar dari siswanya dengan menggunakan fitur progress ini.

10. Edmodo Planner

Digunakan untuk membuat atau mencatat rencana dan juga jadwal kegiatan guru. Fungsi edmodo planner sama seperti buku agenda kerja.

Edmodo menyediakan cara yang aman dan mudah untuk berkomunikasi Perkembangan elearning yang pesat di dunia pendidikan Indonesia sampai pada penggunaan Learning Management System (LSM) di sekolahsekolah..(Witherspoon, 2011) menyimpulkan bahwa Edmodo dapat dilihat sebagai sebuah Learning Management System (LMS) yang dapat memfasilitasi dosen untuk membuat dan mengatur kelas online mereka secara mudah. Situs ini menyediakan cara yang sederhana bagi dosen dan mahasiswa untuk terhubung dan 


\section{J]}

kerjasama secara virtual. Sebagai contoh, dosen dapat mengirimkan kuis dan tugas, memberikan umpan balik, menerima tugas yang diselesaikan oleh mahasiswa, memberikan penilaian, melalukan jajak pendapat, menyimpan dan membagi materi belajar dalam bentuk file maupun tautan (link), maupun mengirimkan pesan atau peringatan kepada seluruh peserta grup belajar. Mahasiswa juga dapat membagi materi belajar, menyerahkan pekerjaan rumah, tugas-tugas dan kuis, menerima umpan balik dari guru, catatan, peringatan maupun vote pada jajak pendapat.

Setiap media pembelajaran memiliki kelebihan dan kekurangan masing-masing, begitu juga dengan Edmodo. Menurut Umaroh (dalam Basori, 2013) kelebihan dari Edmodo antara lain:

1. Membuat pembelajaran tidak bergantung pada waktu dan tempat,

2. Meringankan tugas guru untuk memberikan penilaian kepada siswa,

3. Memberikan kesempatan kepada orang tua atau wali

siswa untuk memantau aktivitas belajar dan prestasi dari putra-putrinya,

4. Membuat kelas lebih dinamis karena memungkinkan interaksi guru dan siswa maupun siswa dengan siswa dalam hal pelajaran maupun tugas,

5. Memfasilitasi kerja kelompok yang multidisiplin,

6. Mendorong lingkungan virtual kolaboratif yang membantu pembelajaran berbasis proses.

Sedangkan kekurangan dari Edmodo sebagai berikut:

1. Penggunaan bahasa program yang masih menggunakan Bahasa Inggris sehingga terkadang menyulitkan guru dan siswa.

2. Belum tersedianya sintaks online secara langsung pada Edmodo.

Untuk menciptakan sebuah komunikasi yang efektif, maka sebuah proses komunikasi harus mengandung unsur-unsur komunikasi. Unsur-unsur komunikasi setidaknya harus 


\section{J]}

terdiri dari enam hal, yaitu sumber, komunikator, pesan, channel, komunikasi itu sendiri, dan efek.

Proses komunikasi ada lima unsur yang harus dipenuhi dalam komunikasi, yaitu:

1. Sumber (source), sering disebut juga pengirim (sender), penyandi (encoder), komunikator (communicator),pembicar a (speaker) atau originator. Sumber adalah pihak yang berinisiatif atau mempunyai kebutuhan untuk berkomunikasi.

2. Penerima (communicant, receiver, recipient, audience), yaitu penerima pesan dari sumber.

3. Pesan (message), yaitu apa yang dikomunikasikan oleh sumber kepada penerima.

4. Media atau saluran (media, channel), yaitu alat atau wahana yang digunakan sumber untuk menyampaikan pesannya kepada penerima.

5. Komunikasi yaitu Unsur-unsur komunikasi yang selanjutnya adalah komunikasi itu sendiri.

6. Efek (effect, impact, influence), apa yang terjadi pada penerima setelah ia menerima

Dalam penggunaan edmodo terdapat efek yang terjadi dalam proses komunikasi. Efek adalah pengaruh kegiatan komunikasi yang di lakukan komunikator kepada komunikan,sehingga terlihat adanya perubahan yang terjadi dalam diri komunikan.atau bisa di artikan Efek yaitu nilai yang ditimbulkan oleh suatu peristiwa atau kejadian yang dialami oleh seseorang atau sekelompok dalam proses pergaulannya atau dalam proses pekerjaannya. Efek dapat berwujud dalam bentuk positif, yaitu berguna bagi penerima efek tersebut, dan bisa berupa efek negatif apabila hal itu 


\section{J]}

mengurangi atau merendahkan merugikan penerima efek tersebut.

\section{Kemudahan}

berkomunikasi menggunakan edmodo ini menjadikan mahasiswa diharapkan dapat memahami dan menggunakan peralatan dan perlengkapan yang ada dalam perkuliahan, sehingga dalam penggunaan edmodo dosen dan mahasiswa terjadi efek komunikasi ketika mahasiswa dalam pembelajaran di rumah dengan daring (online learning atau online classroom) yaitu dengan mampu memahami apa yang di sampaikan dosen dalam perkuliahan tersebut.

Hal ini Donald K Robert mengungkapkan, "efek hanyalah perubahan perilaku manusia setelah diterpa pesan media massa". Oleh karena fokusnya adalah pesan, maka efek harus berkaitan dengan pesan yang disampaikan oleh media . Menurut Steven M Chaffee, efek media dapat dilihat dari tiga pendekatan. Pendekatan pertama adalah efek dari media yang berkaitan dengan pesan ataupun media itu sendiri. Pendekatan kedua adalah dengan melihat jenis perubahan yang terjadi pada diri khalayak komunikasi massa yang berupa perubahan sikap, perasaan dan perilaku atau atau dengan istilah lain dikenal sebagai observasi terhadap khalayak (individu, kelompok, organisasi, masyarakat atau bangsa) yang dikenai efek komunikasi.,Dalam proses komunikasi, pesan dalam media komunikasi dapat menerpa seseorang baik secara langsung mapun tidak langsung. Oleh karena itu, Stamm menyatakan "efek komunikasi massa terdiri atas primary effect dan secondary effect

Institut Agama Islam Darussalam merupakan satusatunya perguruan tinggi berbasis pesantren yang ada di Kabupaten Banyuwangi, terletak di Dusun Blokagung Desa Karangdoro Kecamatan Tegalsari. Saat ini IAIDA memiliki 8 Program Studi dari 3 Fakultas. Fakultas Ekonomi 


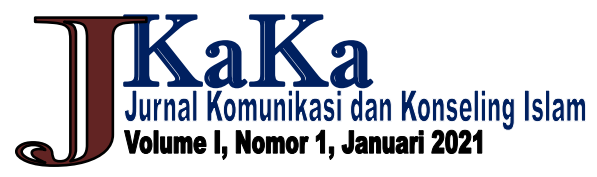

Syariah meliputi Prodi Ekonomi Syariah (ESY) dan Prodi Perbankan Syariah (PSY), Fakultas Dakwah Dan Komunikasi Islam meliputi Prodi Komunikasi Dan Penyiaran Islam (KPI) dan Prodi Bimbingan Konseling Islam (BKI), Fakultas Tarbiyah Dan Keguruan meliputi yaitu Prodi Manajemen Pendidikan Islam (MPI), Prodi Pendidikan Bahasa Arab (PBA), Prodi Tadris Bahasa Indonesia (TBIN) dan Prodi Tadris Bahasa Inggris (TBIG).

Fakultas Dakwah Dan Komunikasi Islam (FDKI) memiliki dua program studi Fakultas Komunikasi Dan Penyiaran Islam (KPI) dan Bimbingan Konseling Islam (BKI). Fakultas Komunikasi Dan Penyiaran Islam (KPI) adalah salah satu jurusan yang dibawah naungan yang di situ terdiri dari beberapa mahasiswa yang aktif di dalamnya, dengan berbagai macam angkatan, diantaranya angkatan KPI 2019, KPI 2018 dan angkatan KPI 2017, KPI sendiri mempunyai beberapa macam 


\section{JI}

pembelajaran e-learning adalah edmodo. E-learning dalam pelaksanaannya diperlukan sebuah media atau yang lebih dikenal dengan sebutan platform untuk menunjang kegiatan $e$ learning itu sendiri.

Subyek dalam penelitian ini yaitu Mahasiswa fakultas dakwah Jurusan Ilmu Komunikasi islam Institut Agama Islam Darussalam, dengan pertimbangan bahwa mahasiswa KPI Dalam mengatasi era pandemik covid 19 ini dengan mewajibkan mahasisawa dalam proses perkuliahan di rumah dengan secara daring atau online learning dengan fasilitas yang terdapat pada Edmodo. Berdasarkan keuntungan yang diperoleh dengan media komunikasi online, dan fiturfitur penting yang dimiliki oleh edmodo, maka penulis tertarik untuk meneliti menginvestigasi persepsi mahasiswa dalam efek edmodo sebagai alat komunikasi dalam pembelajaran.menjadi alternatif dalam proses Pembelajaran daring (online learning atau online classroom) Penggunaan media komunikasi yang mudah dan murah menjadi pilihan utama para mahasiswa sehingga segala kebutuhan informasi antar mahasiswa dapat terpenuhi dan apakah Efek dapat berwujud dalam bentuk positif, yaitu berguna bagi penerima efek tersebut atau bisa berupa efek negatif apabila hal itu mengurangi atau merendahkan merugikan penerima efek tersebut dalam pemahaman dalam pembelajaran (perkuliahan) daring (online learning atau online classroom).

\section{B. PEMBAHASAN}

Mengacu pada fokus penelitian, peneliti akan memaparkan hasil wawancara mengenai Efek edmodo sebagai media komunikasi mahasiswa Komunikasi Dan Penyiaran (KPI) di era pandemik covid 19 dalam perkuliahan secara daring.

Untuk melihat bagaimana Efek aplikasi edmodo dapat dilihat dari respon dosen dan Mahasiswa komunikasi penyiaran 


\section{J]}

islam (KPI) Fakultas Dakwah Komunikasi Islam (FDKI) DI Institut Agama Islam Darussalam (IAIDA) Balokagung Banyuwangi. Adapun hasil yang diperoleh sebagai berikut:

Untuk ungkapan yang pertama datangnya dari wakil rektor 1 institut agama islam darussalam mengenai lembaga memilih edmodo dalam proses pembelajaran di era pandemik (covid 19 ) yaitu sebagai berikut:

"Ya dari sisi-sisi segalanya pelaporannya cek-cek aktivitasnya itu mudah kita menggunakan bisa ngecek aktivitasnya aplikasi yang yang saat itu mudah dideteksi dan sudah bisa memberikan penilaian bisa memberikan pertanyaan ada perbedaan e-learning dan yang bukan bisa digunakan untuk dalam rangka menyampaikan materinya Kenapa ya karena lebih lebih mudah menurut kita lebih mudah daripada model dan sebagainya karena apa lebih familiar lama ada dalam tahun yang lalu saya kenal sudah lebih dari 5 tahun "(Bapak eko Budiono) 12 Agustus 2020

Untuk ungkapan yang kedua datangnya dari dosen Komunikasi Dan Penyiaran Islam (KPI)

"Perkuliahan bisa terlaksana dengan baik, materi bisa tersampaikan.tanya jawab dapat dilakukan, dan tugas untuk mahasiswa juga bisa dikerjakan." (bapak Agus Baihaqi) 23 juli 2020

Ungkapan diatas di perjelas oleh anggota Dosen yang lain yaitu sebagai berikut

"Bagus.jadi alternatif karena tidak bisa kuliah tatap muka" (bapak Aziz) 23 juli 2020

Ungkapan yang ketiga datang dari para mahasiswa komunikasi dan penyiaran islam (KPI) yang menggunakan edmodo dalam perkuliahan di era pandemiik coovid 19.

"Pendapat saya dengan adanya perkuliahan di lakukan dengan cara 


\section{JI}

\begin{tabular}{|c|c|}
\hline daring/online & anaknya \\
\hline menggunakan & kerjaannya mainan hp saja, \\
\hline edmodo cukup membantu & dari sisi lain ada juga yang \\
\hline mahasiswa & pembelajaran \\
\hline mendapatkan haknya & daring ini menjadi alasan \\
\hline tetapi dengan & mereka sebagai \\
\hline pademi ini kita sebagai & mainn hp bukan malah \\
\hline mahasiswa terbatas untuk & mengerjakan tugas karena \\
\hline bisa bertatap muka dengan & males." (fiikri ) 23 juli 202 \\
\hline
\end{tabular}

dosen." (sofyan) 23 juli 2020

Informan yang lain menjelaskan

"Menurut saya, pada konsidi pandemi seperti ini.sudah baik, pemberian materi perkuliahan dari dosen ke mahasiswa juga baik, meskipun bagi saya belum memuaskan sama sekali, dibanding tatap muka dengan dosen seperti biasanya. Tapi ketika pembelajaran berada dirumah, perlu beradaptasi kembali, karena rumah mulanya bukan tempat untuk belajar, jadi perlu dukungan dari orang tua juga, ketika orang tua hanya tau anaknya dirumah hanya pantengin smartphone saja mungkin orang tua mengira Ungkapan Informan lain menjelaskan

$\begin{array}{lr}\text { "Pendapat saya } & \text { tentang } \\ \text { perkuliahan } & \text { online } \\ \text { menggunakan } & \text { aplikasi } \\ \text { edmodo sangan } \quad \text { tidak } \\ \text { memuaskan. Karna kita } \\ \text { tidak bisa ber tatap muka } \\ \text { langsung dengan dosen, dan } \\ \text { ber interaksi sama teman- } \\ \text { teman. Kita susah untuk } \\ \text { menyuarakan pertanyaan dn } \\ \text { pendapat kita tentang } \\ \text { materi yg di sampaikan. Dan } \\ \text { yang saya tidak suka saat } \\ \text { kuliah online dengan } \\ \text { edmodo,tidak } \quad \text { hanya } \\ \text { mahasiswa saja yg tidak } \\ \text { aktif dalam perkuliahan,tapi } \\ \text { sebagian dosen pun tidak } \\ \text { mengisi jam perkuliahan } \\ \text { nya, bahkan ada dosen yang }\end{array}$




\section{JI}

saat sebelum perkuliahan online di laksanakan,beliau tidak pernah masuk saat jam perkuliahan, beliau hanya mengirim tugas dan materi lewat youtube saja saat perkuliahan online ber langsung. Pada intinya, kuliah online selama ini hanya membuang" kuota tanpa ada ilmu dan pengalaman baru yang masuk. Tidak ada timbal baliknya dengan pembayaran UKT yang sudah terbayar,tapi yang di dapat sangat tidak memuaskan." (vina zuhrika) 23 juli 2020

Informan lainnya menjelaskan

"Kalau menurut saya, ada sisi baik dan kurang baik. kalau kurang baiknya, ya saya sebagai mahasiswi perkuliahan menggunakan aplikasi itu, kurang efisien, mengapa karena kita hanya tau materi tanpa penjelasan yang detail, selain itu juga di mata kuliah saya semester ini banyak praktek nya jadi kurang nya praktek mmbuat saya kurang memahami itu. Kalau sisi baiknya ya kita masih bisa melakukan perkuliahan, mendapatkan ilmu di masa pandemik ini Juga bisa dilakukan di rumah saja dengan menjaga kesehatan tubuh." (niia) 23 juli 2020

"Penae ora dadak budal neng kampus dari segi waktu lebih fleksibel Gak penae lebih males ngerjakne tugas cenderung kurang memahami Matari krono ora tatab muka mbek dosen for dosen kurang mantau perkembangan mahasiswa. Ke efektifitasan kurang krono mahasiwa cenderung males dalam mengerjakan tugas entah kurang paham materi utowo faktor lain. Neh sering molor ngerjakne tugas krono fleksibel e wektu dan pemahaman mahasiwa terhadap materi kurang krono kurang pantauan dosen. Kui lek gae 


\section{J}

emodo bedo lek gae zoom opo vc cenderung dosen lebih bisa memantau mahasiwa dan waktu tidak terlalu fleksible". (malik) 23 juli 2020

"Penyebabnya dari individu sendiri mbak, mahasiswa kebanyakan lebih fokus ke kegiatan selain perkuliahan, karna apa? Karna tidak ada dosen yg mengawasi, membimbing, dan mengarahkan dalam proses perkuliahan yang seperti biasanya. Selain itu hp adalah salah satu media yang digunakan untuk perkualiahan daring, tetapi sebaliknya mahasiswa lebih fokus ke hal yang non perkuliahan, seperti mengoperasikan medsos, game, dll." (kotib) 23 juli 2020

Efek edmodo sebagai media komunikasi di era pandemik covid 19 mahasiswa Komunikasi Dan Penyiaran Islam (KPI) Fakultas Dakwah Dan
Komunikasi Islam (FDKI) di Institut Agama Islam Darussalam (IAIDA) Blokagung Karangdaro Tegalsari Banyuwangi.

Hal ini sesuai dengan efek, Efek dapat berwujud dalam bentuk positif, yaitu berguna bagi penerima efek tersebut atau bisa berupa efek negatif apabila hal itu mengurangi atau merendahkan merugikan penerima efek tersebut dalam pemahaman..( Markus Utomo Sukendar, Psikologi Komunikasi: Teori dan Praktek (Yogyakarta: CV Budi Utama, 2017), hal.68.) Efek merupaan perubahan-perubahan yang terjadi di dalam diri audience akibat keterpaan pesan-pesan media.David CaBerlo mengklasifikasikan efek atau perubahan dalam ranah pengetahuan, sikap dan perilaku nyata.Perubahan perilaku biasanya didahului oleh perubahan sikap, dan perubahan sikap biasanya didahului oleh perubahan pengetahuan. Efek diketahui melalui tanggapan khalayak (response audience) yang digunakan sebagai umpan 


\section{J]}

balik (feed back). Jadi, umpan balik merupakan sarana untuk mengetahui efek.Hal ini sesuai dengan teori tentang efek .suatu proses penyampaian pesan dari satu individu kepada individu yang lainnya. (Djamaluddin Rakhmat, 2008: 189).

Dengan demikian efek edmodo sebagai media komunikasi mahasiswa Komunikasi Dan Penyiaran Islam (KPI) di Institut Agama Islam Darussalam (IAIDA) adalah efek positif Edmodo memberi ke mudahan pada guru untuk melakukan pengajaran, berinteraksi dengan siswa, memantau aktivitas siswa di grup, dan melakukan evalusi. Dan efek negatif yaitu IE;dmkodo tidaAk tersedia laya nan untuk mengirim pesan tertutup antar sesama siswa, tidak adanya fasilitas tagging, Edmodo merupakan produk baru yang masih dalam pengembangan dan belum sempurna.

\section{KESIMPULAN}

Efek Edmodo sebagai media komunikasi di era pandemik codid 19 pada mahasiswa Komunikasi Dan Penyiaran Islam (KPI) di Institut Agama Ilam Darussalam (IAIDA) adalah efek positif dan efek negatif, bentuk positif yaitu berguna bagi penerima efek tersebut seperti Edmodo memberi kemudahan pada guru/dosen untuk melakukan pengajaran, berinteraksi dengan mahasiswa, memantau aktivitas mahasiswa di grup, dan melakukan evalusi. Dan efek negatif apabila hal itu mengurangi atau merugikan penerima efek tersebut dalam pemahaman dalam perkuliahan.

Berdasarkan hasil penelitian yang menunjukkan adanya efekEdmodo sebagai media komunikasi di era pandemik covid 19 pada mahasiswa Komunikasi Dan penyiaran ilam (KPI) di Institut Agama Ilam Darussalam (IAIDA) adalah efek positif dan efek negatif. Maka penulis memberikan beberapa saran sebagai berikut: 


\section{JI}

Dengandilakukannyapene litianinidanterbuktiadanyapeng aruhhasil belajar dengan menggunakan media edmodo pada pembelajaran pendidikan agama Islam. Sekolah diharapkan mampu menyediakan dan menggunakan media yang baik dalam proses belajar mengajar agar tercapainya tujuan pembelajaran. Dan diharapkan dengan adanya media edmodo ini dapat menjadi referensi baru untuk menggantikan media konvensional yang tidak tesediasepenuhnya.

Dengan dilakukannya penelitian ini dan terbukti adanya pengaruh hasil belajar dengan menggunakan media edmodo pada pembelajaran pendidikan agama Islam. Sekolah diharapkan mampu menyediakan dan menggunakan media yang baik dalam proses belajar mengajar agar tercapainya tujuan pembelajaran. Dan diharapkan dengan adanya media edmodo ini dapat menjadi referensi baru untuk menggantikan media konvensional yang tidak tesediasepenuhnya.

Berdasarkan penelitian ini diharapkan guru mampu menggunakan media yang baik dan tepat, serta guru diharapkan dapat memilih dengantepat media sesuai materi yang diajarkan. Guru diharapkan dapat mengikuti perkembangan jaman khususnya perkembangan teknologi untukmemberikan pelajaran terhadap pesertadidik.

Peserta didik diharakan mampu menggunakan media khususnya teknologi dengan baik dalam pembelajaran. Terdapat banyak sekali aplikasi atau media yang membantu peserta didik untuk meningkatkan hasil belajar salah satunya adalah media edmodo. Sehingga peserta didik mampu mengimbangi perkembangan. teknologi dalam ranah pendidikan 


\section{DAFTAR PUSTAKA}

Soerjono,Soekanto.1982.Sosiologi

Suatu Pengantar. Jakarta:CV.

Rajawali. Ngalimun. 2017.

Ilmu Komunikasi.

Yogyakarta: Pustaka Baru

Press.

Arifin, Noor. 2007. Ilmu Sosial

Dasar. Bandung: CV.

Pustaka Setia.

Effendy, Uchjana Onong. 2004.

Ilmu Komunikasi Teori dan

Prkatek. Bandung: PT.

Remaja Rosdakarya.

Effendy, Onong Uchjana. (2003).

Ilmu, Teori dan Filsafat

Komunikasi. Bandung:Citra

Aditya Bakti

Mulyana Deddy. 2005. Ilmu

Komunikasi Suatu Pengantar.

Bandung: PT Remaja

Rosdakarya

Sendjaja, S. Djuarsa. 1999. Teori

Komunikasi. Universitas

Terbuka. Jakarta.

Dalam Imam Gunawan. 2015.

Metode Penelitian Kualitatif:

Teori dan Praktik. Jakarta:

Bumi Aksara.

Lexy J. Moleong ,Metodologi

Penelitian Kualitatif

(Bandung: PT. Remaja

Rosdakarya, 2015).

Sugiyono.2006.Metode Penelitian

Kuantitatif, Kualitatif dan R \&

D.Bandung:Alfabeta.
Keith R. Stamm dan John E.

Bowesl990The

Mass

Communications

ProcessKendall

HuntpublishingIowa

Zhang, D., Zhou, L., \& Briggs, R. 2006. Instructional Video in E-learning: Assessing the Impact OfInteractive video On learning Effectiveness. Informatione Management.Vol . 43.Issue 1. P. 15-27.

Zwang, J. 2010. Edmodo:A Free, Secure, SocialNetworking Site For School.

(Online),(http://www.eschoolne ws.com/2010/12/15/edmodo -a-free-secure-social

Networkingsitefor-school/. Diakses 29 Juli 2020)

Http://Dickysyuhada.Blogspot.C om/2011/01/HakikatOrganisasi.Html

Https://www.edmodo.com/, (Online diakses tanggal 29 juli 2020) 


\section{TKaKa}

Jurnal Komunikasi dan Konseling Islam

Volume I, Nomor 1, Januari 2021 